\title{
A Colossal Tsunami, an Offspring of a Gigantic Under-Water Earthquake
}

\author{
Dr.(Prof.) V.C.A. NAIR* \\ Educational Physicist and Research Guide at Shri. JJT University, Rajasthan-333001, India \\ *nairvca39@gmail.com
}

\begin{abstract}
Most of the contents in the paper are excerpts from the chapter on Tsunamis in the Ph.D Thesis of the author [5] and the same suitably modified to fit into as a research paper so as to get free and direct access to readers. The paper begins with a historical account on tsunamis. A brief account of some ten most colossal tsunamis of recent times is given. An elementary treatment of wave motion makes the paper suitable for both the common man and scientist. The situations when the tsunami strikes the land with the crest and with the trough are separately dealt with. Protection and warnings from tsunamis are briefly dealt with. Some of the diagrams are drawn by the author himself and the paper ends with a conclusion.
\end{abstract}

Keywords: Amplitude, Crest, Draw-down, Run-up, Trough, Tsunami, Wavelength.

\section{REVIEW OF LITERATURE}

\section{INTRODUCTION}

\subsection{Historical:}

1.11 The Origin and the Name: 'Tsunami' is a Japanese word, 'tsu' means 'harbor' and 'nami' means 'wave'. In the Tamil language in India, the word is 'aazhiperalai'; In the Acehnese language, it is ie beuna or alon buluek. On Simeulue island of Sumatra in Indonesia in the Defayan language, the word is 'Smong', while in the Siqulai language it is 'emong'. The Greek historian Thucydides suggested in $426 \mathrm{BC}$ that tsunamis were related to submarine earthquakes, but the real research started in the $20^{\text {th }}$ century. As a matter of historical interest, see Fig.1 and 2. In the Fig. 1 is seen the turmoil of the 1755 Lisbon, Portugal earthquake and tsunamis. In the other figure is seen the Russians of Pavel Lebedev-Lastochkin meeting the Japanese after their ships being tossed inland by a tsunami in the year 1779 .

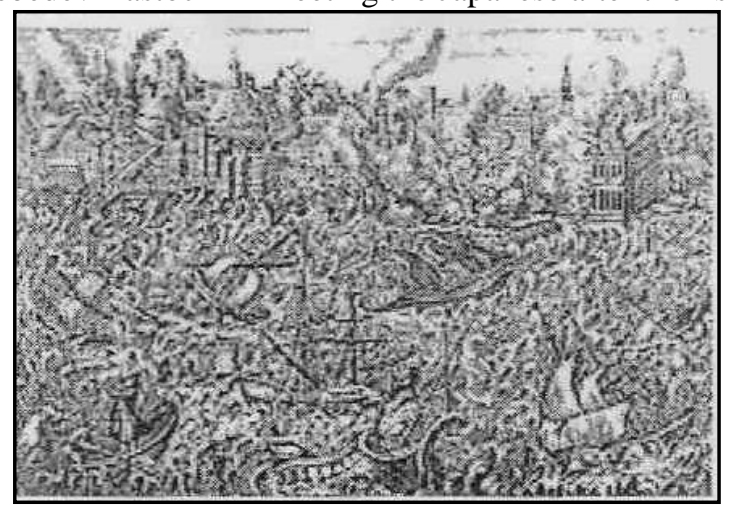

Fig. 1 The turmoil of Lisbon earthquake and tsunami in 1755

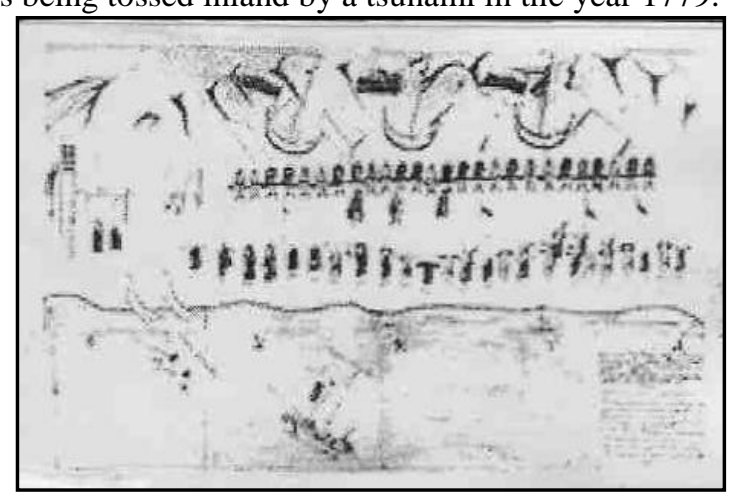

Fig. 2 The distressed Russians meeting the Japanese after a tsunami in 1779 .

1.2 The Ancient Tsunamis: From a historical point of view, the Humboldt State University [7] under the auspices of National Oceanic and Atmospheric Administration (NOAA) of the United States Geological Survey (USGS) has published a series of Earthquake-caused tsunamis and the same, in a chronological order, I would like to enumerate here: The same is coupled with some 10 worst tsunamis published by Campbell Phillips [1] which are marked with asterisk in the literarure.

Some 8,000 years ago: A volcano caused an avalanche in Sicily 8,000 years ago that crashed in[ ]to the sea at $200 \mathrm{mph}$, triggering a devastating tsunamithat spread across the entire Mediterranean Sea. There are no historical records of the event - only geological records - but scientists say the tsunami was taller than 10-story building. 


\title{
IARJSET

*Enshunada Sea, Japan - 20 September 1498 An earthquake, estimated to have been at least magnitude 8.3, caused tsunami waves along the coasts of Kii, Mikawa, Surugu, Izu and Sagami. The waves were powerful enough to breach a spit, which had previously separated Lake Hamana from the sea. There were reports of homes flooding and being swept away throughout the region, with a total of at least 31,000 people killed.

*Ise Bay, Japan - 18 January 1586. The earthquake that caused the Ise Bay tsunami is best estimated as being of magnitude 8.2. The waves rose to a height of $6 \mathrm{~m}$, causing damage to a number of towns. The town of Nagahama experienced an outbreak of fire as the earthquake first occurred, destroying half the city. It is reported that the nearby Lake Biwa surged over the town, leaving no trace except for the castle. The Ise Bay tsunamis caused more than 8000 deaths and a large amount damage

*Nankaido, Japan - 28 October 1707. A magnitude 8.4 earthquake caused sea waves as high as $25 \mathrm{~m}$ to hammer into the Pacific coasts of Kyushyu, Shikoku and Honshin. Osaka was also damaged. A total of nearly 30,000 buildings were damaged in the affected regions and about 30,000 people were killed. It was reported that roughly a dozen large waves were counted between $3 \mathrm{pm}$ and $4 \mathrm{pm}$, some of them extending several kilometres inland at Kochi. 8

\begin{abstract}
*Nov. 1, 1755: After a colossal earthquake of magnitude 8.5 destroyed Lisbon, Portugal and southern Spain and the ensuing tsunami-affected waves as far away as Carlisle Bay and Barbados. Much of Europe was rocked, people took refuge by boat. The tsunami and the great fires. altogether, killed more than 60,000 people in the Portugal, Morocco and Spain.
\end{abstract}

*9. Ryuku Islands, Japan - 24 April 1771. A magnitude 7.4 earthquake is believed to have caused a tsunami that damaged a large number of islands in the region; however, the most serious damage was restricted to Ishigaki and Miyako Islands. It is commonly cited that the waves that struck Ishigaki Island was $85.4 \mathrm{~m}$ high, but it appears this is due to a confusion of the original Japanese measurements, and is more accurately estimated to have been around 11 to $15 \mathrm{~m}$ high. The tsunami destroyed a total of 3,137 homes, killing nearly 12,000 people in total.

*8. Northern Chile - 13 August 1868. This tsunami event was caused by a series of two significant earthquakes, estimated at a magnitude of 8.5, off the coast of Arica, Peru (now Chile). The ensuing waves affected the entire Pacific Rim, with waves reported to be up to $21 \mathrm{~m}$ high, which lasted between two and three days. The Arica tsunami was registered by six tide gauges, as far off as Sydney, Australia. A total of 25,000 deaths and an estimated US\$ 300 million in damages were caused by the tsunami and earthquakes combined along the Peru-Chile coast.

*27 August 1883: Eruptions from the Krakatoa caldera volcano fueled a tsunami as high as $37 \mathrm{~m}$ that drowned 36,000 people in the towns of Anjer and Merak of Indonesian Islands of western Java and southern Sumatra. The strength of the waves pushed coral blocks as large as 600 tons onto the shore. The sea was reported to recede from the shore at Bombay (now Mumbai), India.

*7. Sanriku, Japan - 15 June 1896. This tsunami propagated after an estimated magnitude 7.6 earthquake occurred off the east coast of Sanriku, Japan. The tsunami was reported at Shirahama to have reached a height of $38.2 \mathrm{~m}$, causing damage to more than 11,000 homes and killing some 22,000 people. Reports have also been found that chronicle a corresponding tsunami hitting the east coast of China, killing around 4000 people and doing extensive damage to local crops.

1 April 1946: The April Fool tsunami, triggered by an earthquake in Alaska, killed 159 people, mostly in Hawaii.

9 July 1958: Regarded as the largest recorded in modern times, the tsunami in Lituya Bay, Alaska was caused by a landslide triggered by an 8.3 magnitude earthquake. Waves reached a height of 1,720 feet (576 meters) in the bay, but because the area is relatively isolated and in a unique geologic setting the tsunami did not cause much damage elsewhere. It sank a single boat, killing two fishermen.

22 May 1960: The largest recorded earthquake, magnitude 8.6 in Chile, created a tsunami that hit the Chilean coast within 15 minutes. The surge, up to 75 feet ( 25 meters) high, killed an estimated 1,500 people in Chile and Hawaii.

27 March 1964: The Alaskan Good Friday earthquake, magnitude between 8.4, spawned a 201-foot (67-meter) tsunami in the Valdez Inlet. It traveled at over $400 \mathrm{mph}$, killing more than 120 people. Ten of the deaths occurred in Crescent City, in northern California, which saw waves as high as 20 feet (6.3 meters).

23August 1976: A tsunami in the southwest Philippines killed 8,000 on the heels of an earthquake.

17 July 1998: A magnitude 7.1 earthquake generated a tsunami in Papua New Guinea that quickly killed 2,200. 


\section{IARJSET

*26 December 2004 Sumatra, Indonesia. The 9.1 magnitude earthquake off the coast of Sumatra was estimated to occur at a depth of $30 \mathrm{~km}$. The fault zone that caused the tsunami was roughly $1300 \mathrm{~km}$ long, vertically displacing the sea floor by several metres along that length. The ensuing tsunami was as tall as $50 \mathrm{~m}$, reaching $5 \mathrm{~km}$ inland near Meubolah, Sumatra. This tsunami is also the most widely recorded, with nearly one thousand combined tide gauge and eyewitness measurements from around the world reporting a rise in wave height, including places in the US, the UK and Antarctica. An estimated US \$10b of damages is attributed to the disaster, with around 230,000 people reported dead. The death rate increased because of lack of medical aid and poor sanitary conditions.

The quake was named the Sumatra-Andaman earthquake, and the tsunami has become known as the 2004 Indian Ocean tsunami. Those waves traveled the globe - as far as Nova Scotia and Peru.

* 11 March 2011 North Pacific Coast, Japan. A powerful tsunami travelling 800km per hour with $10 \mathrm{~m}-\mathrm{high}$ waves swept over the east coast of Japan, killing more than 18,000 people. The tsunami was spawned by an 9.0 magnitude earthquake that reached depths of $24.4 \mathrm{~km}$ - making it the fourth-largest earthquake ever recorded. Approximately 452,000 people were relocated to shelters, and still remain displaced from their destroyed homes. The violent shaking resulted in a nuclear emergency, in which the Fukushima Daiichi nuclear power plant began leaking radioactive steam. The World Bank estimates that it could take Japan up to five years to financially overcome the $\$ 235$ billion damages.

*The most colossal and gigantic Tsunamis

\section{CAUSE OF A TSUNAMI}

2.1 The Main Cause: Stephen A. Nelson [6] of Tulane University has produced a diagrammatic illustration of the generation of a tsunami from earthquakes and the same is shown Fig.3.

The most destructive tsunamis are generated from large, shallow earthquakes with an epicenter or fault line near or on the ocean floor. These usually occur in regions of the earth characterized by tectonic subduction along tectonic plate boundaries. The high seismicity of such regions is caused by the collision of tectonic plates. When these plates move past each other, they cause large earthquakes, which tilt, offset, or displace large areas of the ocean floor from a few kilometers to as much as a 1,000 km or more. The sudden vertical displacements over such large areas, disturb the ocean's surface, displace water, and generate destructive tsunami waves. The waves can travel great distances from the source region, spreading destruction along their path. For example, the Great 1960 Chilean tsunami was generated by a magnitude 9.5 earthquake that had a rupture zone of over $1,000 \mathrm{~km}$. Its waves were destructive not only in Chile, but also as far away as Hawaii, Japan and elsewhere in the Pacific. Another colossal tsunami of recent origin is the one on 26 December 2004 caused by an earthquake of magnitude 9.3 erupted off the western coast of Sumatra. The sea level at the source was lifted to over 10 meter and killed over 200,000 people in 14 countries bordering the Indian Ocean worldwide.

It should be noted that not all earthquakes generate tsunamis. Usually, it takes an earthquake with a Richter magnitude exceeding 7.5 and the force shifting the ocean floor vertically is required to produce a destructive tsunami.

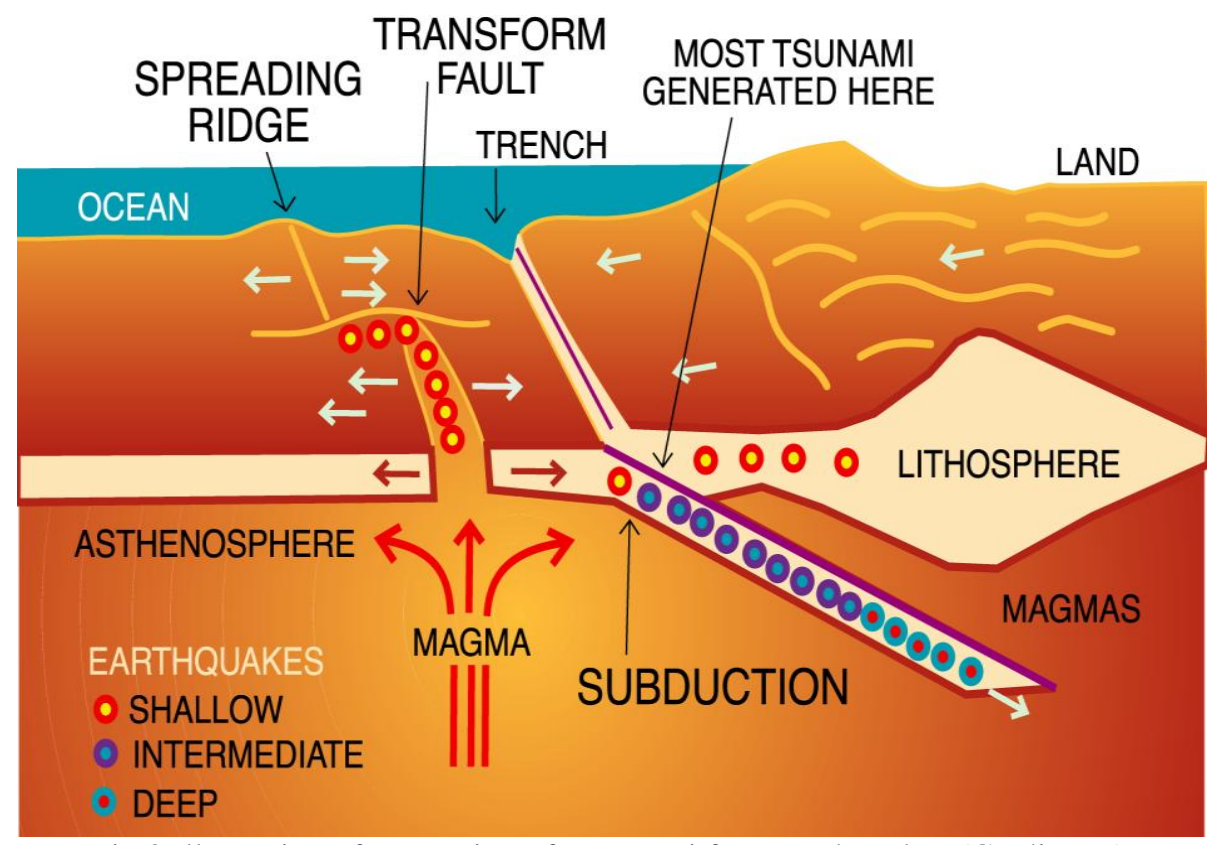

Fig.3 Illustration of generation of a tsunami from earthquakes (Credit: [6]) 


\section{International Advanced Research Journal in Science, Engineering and Technology}

ISO 3297:2007 Certified

Vol. 5, Issue 1, January 2018

Most tsunamis are generated by shallow, great earthquakes at subduction zones. More than $80 \%$ of the world's tsunamis occur in the Pacific along its Ring of Fire subduction zones. When a great earthquake ruptures, the faulting can cause vertical slip that is large enough to disturb the overlying ocean, thus generating a tsunami that will travel outwards in all directions.

After the 11 March 2011 Japanese tsunami which killed more than 18,000 people, the Indian daily, Times of India, Mumbai, [10](date unrecorded) came out with an exhaustive news item with a self-explanatory illustration titled, "Makings of a Tsunami" and the same is shown Fig.4.

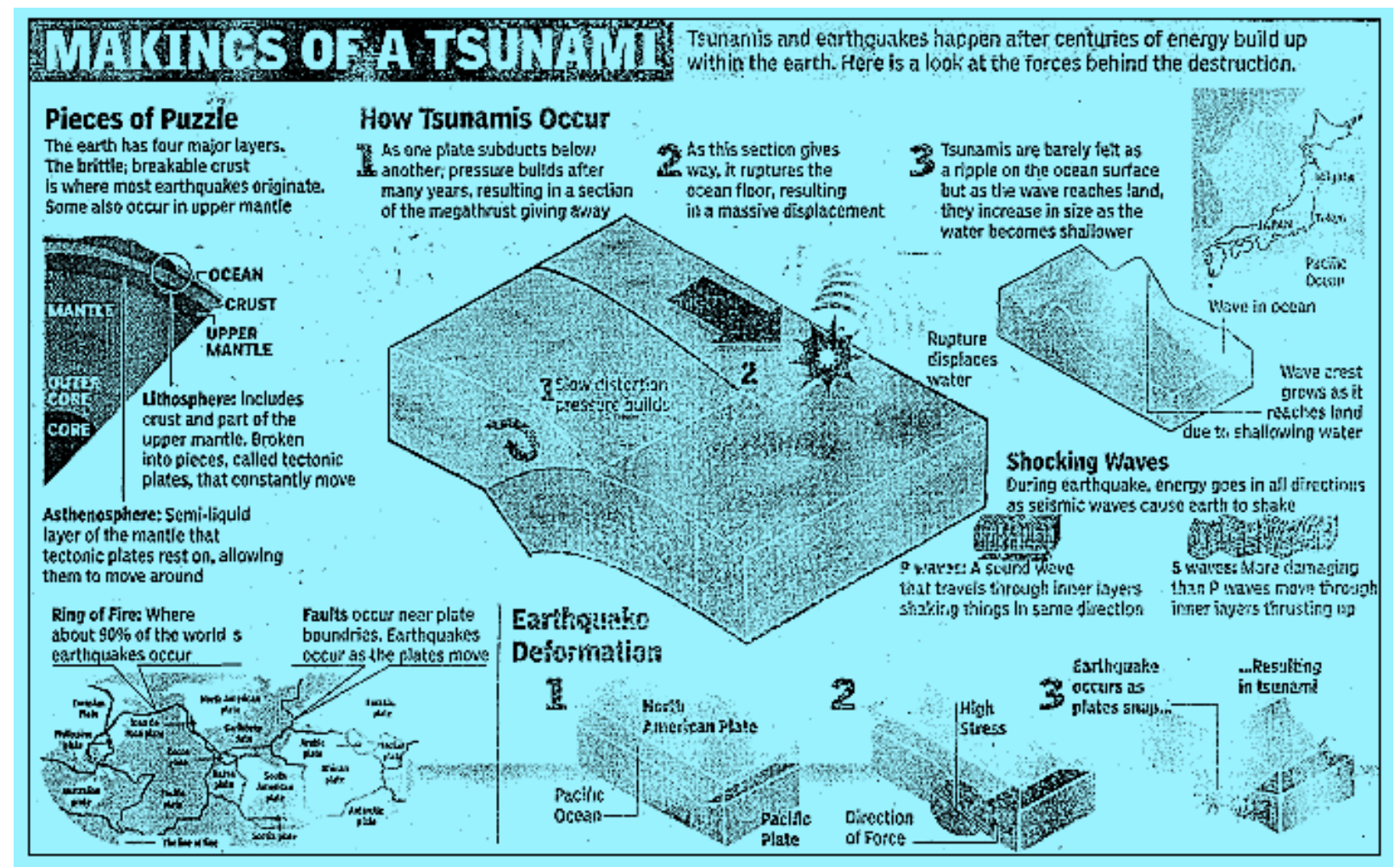

Fig.4 An illustration regarding generation of a tsunami from Times of India, Mumbai [10]

2.2 Other Causes: Earthquakes, volcanic eruptions, any underwater explosions (including nuclear explosions), landslides, glacier calvings, meteorite impacts and other disturbances above or below water all have the potential to generate a tsunami.

The eruption of Krakatau in the Straights of Sunda, between Java and Sumatra, in 1883 generated at least three tsunami that killed 36,417 people.

Landslides moving into oceans, bays, or lakes can also generate tsunami. Most such landslides are generated by earthquakes or volcanic eruptions. A large landslide or debris avalanche fell into Lituya Bay, Alaska in 1958 causing a wave with a run-up of about $60 \mathrm{~m}$ as measured by a zone completely stripped of vegetation.

As for under-water explosions, a nuclear test carried out by the United States in the Marshall Islands in the 1940s and 1950s generated tsunami.

Regarding Meteorite Impacts, no historic examples are known to have produced a tsunami. But, the records show that the apparent impact of a meteorite at the end of the Cretaceous Period, about 65 million years ago near the tip of what is now the Yucatan Peninsula of Mexico, produced tsunami that left deposits all along the Gulf coast of Mexico and the United States.

\section{THE TSUNAMI OSCILLATION}

3.1 The Characteristics of a Water Wave: Various characteristics of a water wave are shown in Fig. 5. The velocity v of a wave is given

$$
\mathrm{v}=\mathrm{n} \lambda=\frac{\lambda}{\mathrm{T}}
$$




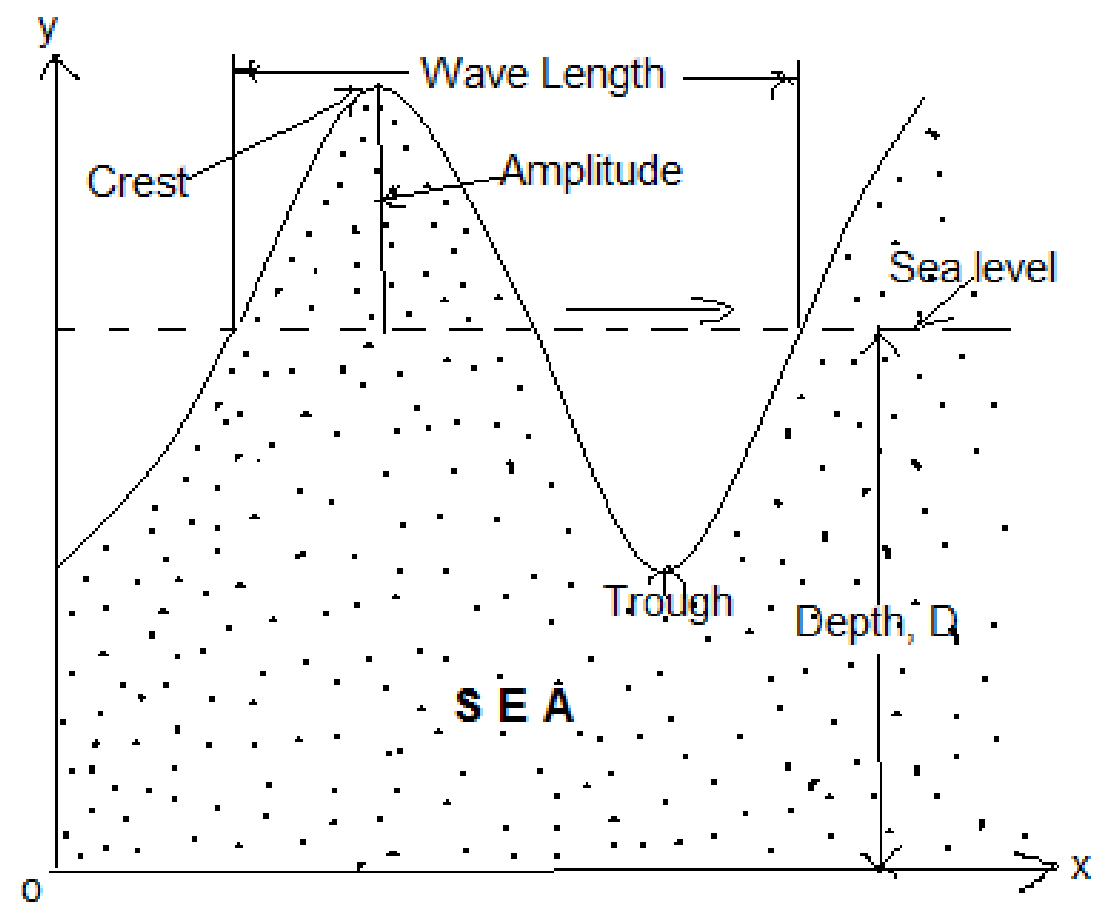

Fig. 5 Characteristics of a sea wave

where $\mathrm{n}$ is the frequency, $\lambda$.the wavelength and $\mathrm{T}$ the periodic time. For a shallow water wave the velocity is, however, a function of the depth $\mathrm{D}$ of the sea and the same is given by

$$
\mathrm{v}=\sqrt{\mathrm{g} D}
$$

where $\mathrm{g}$ is the gravitational acceleration the value of which is $9.8 \mathrm{~m} \mathrm{~s}^{-2}$

If we take the mean position of the wave as the sea level, Crest is the highest point and Trough the lowest point of the wave. The distance from the mean position to either a crest or a trough is known as the Amplitude. The distance between any two consecutive identical positions of the wave is called wavelength. The wavelength for a normal water wave such as a tidal wave can be at the most 100 meter and that for a tsunami wave can be 100 kilometer or even more.

3.2 The Tsunami in Action: The tsunami being natural and most unpredictable, the fear is both on the sea and more on the land. The fear on the sea for sailing ships and on the land for population and building structures. One is not sure which part of the giant tsunami wave is approaching, whether a trough or a monster crest. I have dealt with each case separately.

The maximum speed of a tsunami of wavelength $100 \mathrm{~km}$ is about, say $800 \mathrm{~km} / \mathrm{hr}$ so that the frequency is about 8 per hour thus making a period of 0.125 hour which is equal to 7.5 minutes. That is to say that in 7.5 minutes each wave will be repeated. Taking a worst case of the wavelength $100 \mathrm{~km}$, a crest of water of sizeable height will appear for a distance of $50 \mathrm{~km}$ which is half the wavelength and damaging property and killing people on its way. It takes less than 4 minutes (approximately half the period of 7.5) for a trough to appear and will create a no water region on the shore for few seconds or less than a minute before the water of the crest which has gone earlier starts flowing back into the sea to make one feel that the tsunami has gone back. But, this consolation is a short-lived one because after 3 or 4 minutes will appear the monster crest again to repeat the same process Thus, the tsunami oscillates in this manner.

I have correlated some of my own ideas with the events given by Stephen Nelson [6].A phenomenon called "Drawback" or "Draw-down" occurs when the trough of the tsunami first reaches the coast and will make one feel that there is a considerable drop of sea level in that region of the coast. The drawdown is immediately followed by the crest and takes people by surprise and this phenomenon is called "Run-up". All the three parameters, velocity, period and wavelength of these waves are so large that it may take a long time, sometimes hours for the successive crests to reach the shore. As explained earlier, the first wave may not be the largest, but the following ones may be. One has to wait till 
all the waves pass and it may take hours for in it. Recent studies on tsunamis have indicated that the $1^{\text {st }}, 3^{\text {rd }}$ and $5^{\text {th }}$ waves were the largest.

3.21.ATrough approaching the shore: Let us now see the situation when a trough first approaches the shore. This is shown in Fig.6. There is a sudden decrease in water level at the shore. The water starts flowing fast from the shore to the interior something like a major low tide. This is an indication of trough of the tsunami being formed at the shore. This is a good warning sign, but the available time is less. The time will be more for a severe earthquake. It should be noted that the time will be only in terms of minutes and not hours. Local population can prepare themselves to get saved from the hazard and get themselves prepared to face the following monster crest. The low water level observed is a local phenomenon confined only to the region where tsunami is struck. It is just the trough of the tsunami being formed. It can very well drag debris and suck people into the sea. This is called "Drawback" and the same is shown in Fig.7.

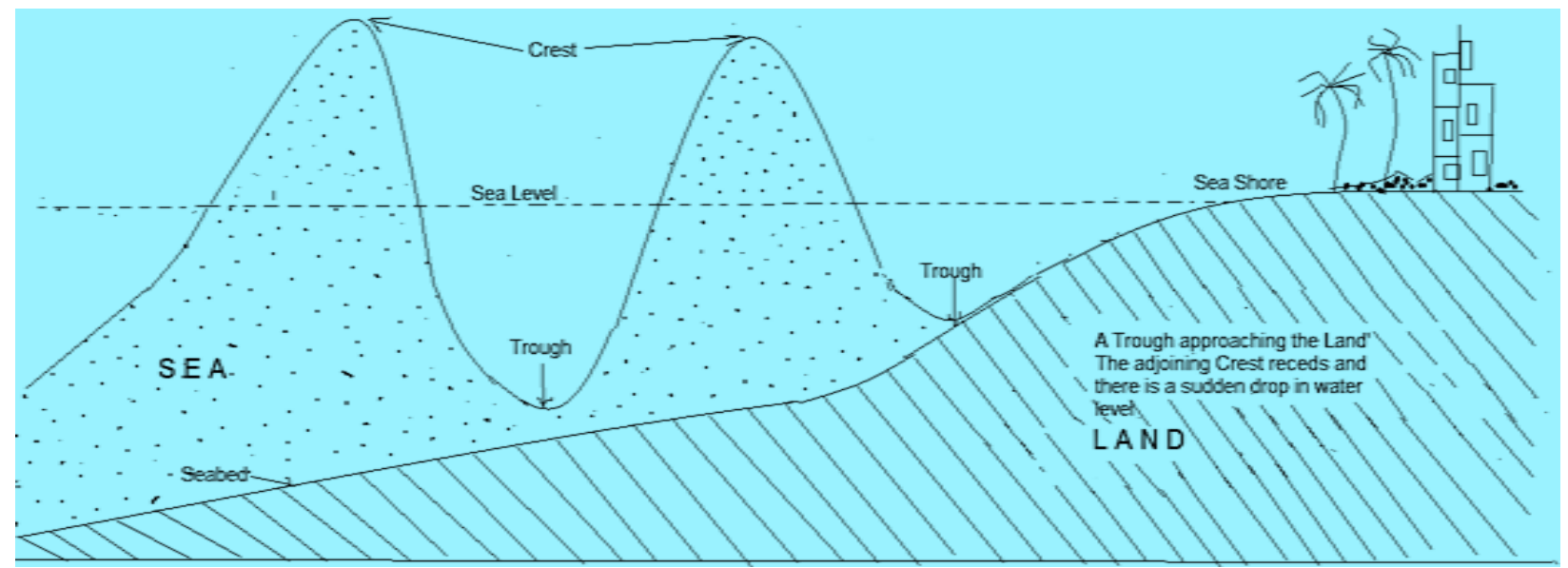

Fig.6 A tsunami trough approaching the shore [5]

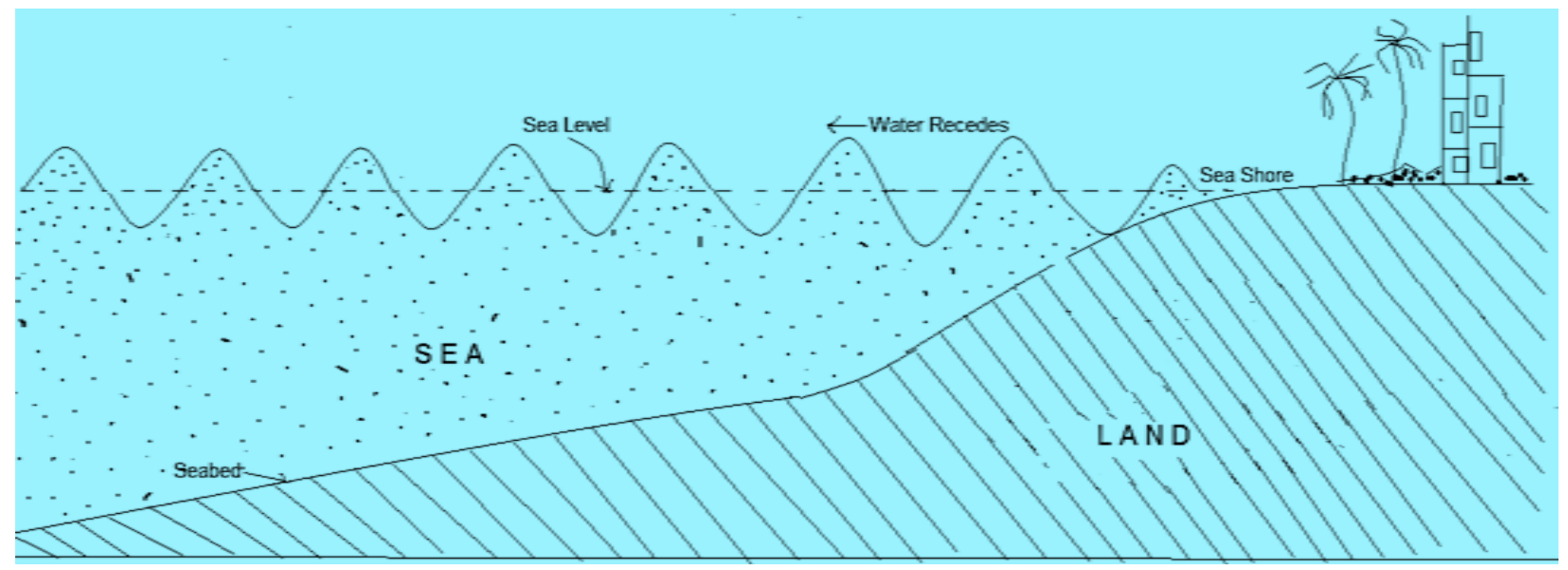

Fig.7 The Retreat of initial thrust (Drawback) [5]

3.22. A Crest approaching the shore: Let us now see the situation when a Crest first approaching the shore which is shown in Fig.8. The drawback is followed by the crest approaching the shore. As seen in the fig., the crest has already reached just above the shore. There is a downpour of water with a thrust and the water level rises. This is known as "Run-Up" and expressed in meters above normal sea level. The run-up from the same tsunami may be variable at different places depending upon the geographical shape of the coast-line. It so happens that the effect may be much less in some place, but violent in other places on the coast-line. The crest reaching the shore takes people by surprise and the water suddenly enters some 300 meters or more carrying loose objects and debris. The run-up height is 30 meters or more. 


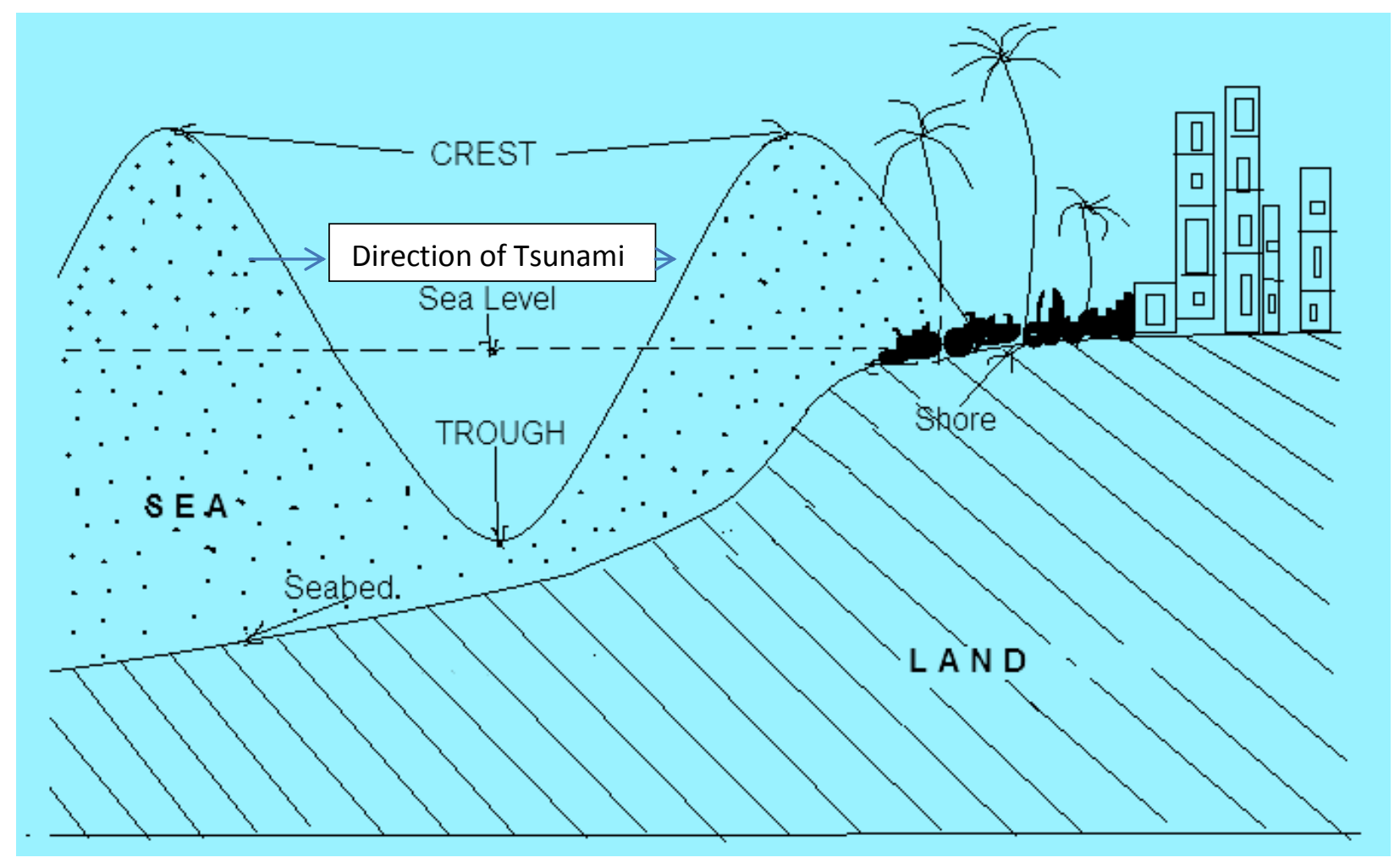

Fig.8 The Crest of the tsunami approaching the shore (Run-up) [5]

3.3 Damage and destruction: Apart from innumerable loss of lives, there is lot of damage to ships on the sea and buildings and structures in the coastal regions. Eric Christiansen and Kenneth Hamblin [2] has shown in Fig.9 the extent of damage to ships done by the 1964 tsunami of the Alaskan earthquake. The picture shows the bay at Seward with an overturned ship, a demolished truck and torn-up dock strewn with logs and scrap metal attest to the power of wave. A section of the waterfront slid into the bay. Waves spread in all directions destroying rail road docks washing out rail, road and highway bridges.

The Indian daily, Times of India, Mumbai [9] has produced a picture (Fig.10) of Impromptu Junkyard where vehicles are piled up in Kesennuma, Miyagi Prefecture, Japan after the tsunami of 11 March 2011.

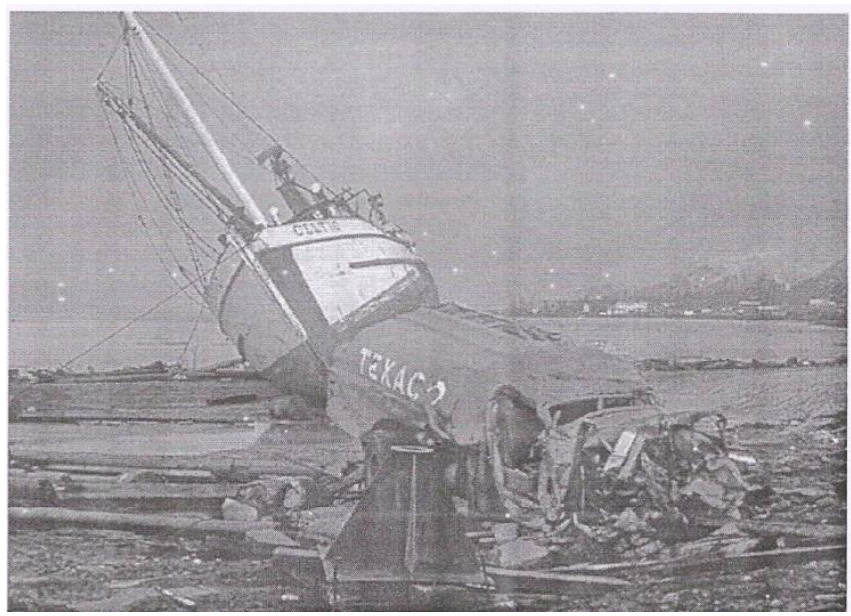

Fig.9 The extent of damage done to a ship [2]

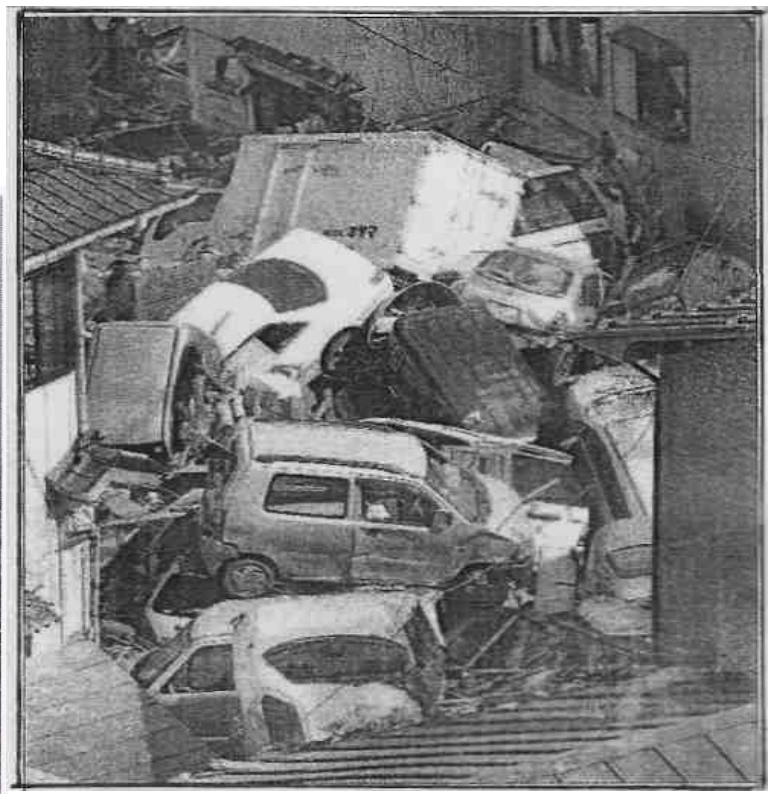

Fig.10 The junk yard of toppled vehicles [9] 


\section{IARJSET

3.4 Quantitative Treatment: Derek K. Miller [4] and Hock Lye Koh, et.al [3] have quantitatively and mathematically dealt with tsunamis. Miller gives an eye witness account of Ms Petula Brown, who was enjoying her vacation in Phuket, Thailand when the tsunami hit and she was the first to witness the action of tsunami and she said:

"I am still confused about the water retreating as where we were the water disappeared for 5 or nearly 10 minutes allowing people to wander out to investigate more. Why should this water remain for so long? The first wave was more like a fast rising tide, but the waves to follow were crashing monsters destroying everything on its way. Fortunately, the sleeping rooms in our resort were 105 steps up from the beach. So people were only injured, but no one died."

For a tsunami to occur, the type of earthquake, its magnitude, the topography of the sea along with the marine geology of the sea are all important. A tsunami wave train moves as ocean swells do, by raising and lowering the water level as it passes by. In the tsunami of 2004, the water that drowned people in Somalia was African water and that in Thailand was Thailand water. The water is carried on and on due to the tremendous energy of the wave comparable to some nuclear explosions. The energy is hardly dissipated but gets decreased when it meets with obstruction on land. Any after-quake tremor adds to the energy. A tsunami in the mid ocean will take a long time for the water level to rise. Many of the tsunamis occur in Japan because of its seismic vulnerability and the entire country consisting of islands surrounded by water. Mild earthquakes of magnitude 4 or less are common in Japan and the resulting tsunamis from them are not severe. Such tsunamis are called local or regional tsunamis. Those tsunamis which are ferocious in their behavior of damaging property and deaths have been rightly called as mega tsunamis. Sometimes due to low atmospheric pressure and depressions that cause tropical cyclones, create a storm surge create tides much higher than the usual high tides and resemble tsunamis. Such tsunamis are called Meteotsunamis.

George Pararas-Carayannis [8] has given a historical summary of early tsunami research in the United States. The research started in the University of Hawaii as early as 1946 after the end of Second World War. What prompted the Americans to open a research center was the damage and deaths occurred in the tsunami that struck Hawaii on 1 April 1946. They have established a Pacific tsunami Warning Center (PTWC) at Honolulu, Hawaii.

The author has dealt with some formula to find out the intensity and magnitude for a tsunami. The intensity, I is expressed as the sum of a pure number $\frac{1}{2}$ and another term with the logarithm to the base 2 of the average wave height, $\mathrm{H}_{\mathrm{av}}$. That is,

$$
\mathrm{I}=\frac{1}{2}+\log _{2} \mathrm{H}_{\mathrm{av}}
$$

This scale is known as the Solovievimamura Tsunami intensity scale.

Now, coming to magnitudes, there is a scale proposed by Murty and Loomis known as the ML Scale and based on the potential energy. As there were difficulties in calculating the potential energy of a tsunami, this scale is disdcarded. They took into consideration the maximum tsunami amplitude, $\mathrm{h}$ expressed in meters and measured by a tide gauge at a distance $\mathrm{R}$ from the epicenter. If $\mathrm{M}_{\mathrm{t}}$ is the magnitude scale, then

$$
\mathrm{M}_{\mathrm{t}}=\mathrm{a} \log \mathrm{h}+\mathrm{b} \log \mathrm{R}=\mathrm{D} \ldots \ldots \ldots \ldots(4)
$$

where $\mathrm{a}, \mathrm{b}$ and $\mathrm{D}$ are constants.

The $26^{\text {th }}$ December 2004 tsunami was a real and ferocious offspring of the gigantic earthquake of magnitude 9.3 which has taken the world by surprise and I would like to present little more information regarding the same.

In the research paper by Hock Lye Koh, et al.[3] have mentioned that an active research has been initiated in the Universiti* Sains Malaysia (USM) immediately after the infamous and deadly earthquake of the 2004 Banda Aceh and the ensuing Andaman mega tsunami that killed over 200,000 people. The authors have developed Disaster Research Nexus (DRN) in their School of Civil Engineering of the University in order to conduct active collaborative research in the subject including landslides. A tsunami simulation model called TUNA is applied to the 2004 tsunami. They have also discussed the role of mangroves in the control of disaster. The main aim of DRN is to create awareness and implementation both nationally and internationally regarding hazards, prediction, preparedness and mitigation leading to effective emergency management programs pertaining to all disasters in general and earthquakes and tsunamis in particular. The details arrived at by the authors regarding the deadly tsunami of 2004 is given below :

Date: 26 December 2004

Time: 00:58:53 UTC (08:58:53 Malaysian time)

Location: Western coast of Banda Aceh, North Sumatra

Water lifted at the source by: 12 meters

Quantity of water lifted upwards: 200 trillion tons

Magnitude: 9.3 


\section{International Advanced Research Journal in Science, Engineering and Technology}

ISO 3297:2007 Certified

Vol. 5, Issue 1, January 2018

Direction: Initial tsunami wave split in two fronts; one moving eastwards towards Malaysia and Thailand while the second towards Sri Lanka and India.

A mathematical treatment (Credit: [3]) for tsunami is based on Shallow Water Equations (SWE) which are depth averaged and subject to conservation of mass and momentum.

They are:

$\frac{\partial \eta}{\partial \mathrm{t}}+\frac{\partial \mathrm{M}}{\partial \mathrm{x}}+\frac{\partial \mathrm{N}}{\partial \mathrm{y}}=0$

$\frac{\partial \mathrm{M}}{\partial \mathrm{x}}+\frac{\partial}{\partial \mathrm{x}}\left(\frac{\mathrm{M}^{2}}{\mathrm{D}}\right)+\frac{\partial}{\partial \mathrm{y}}\left(\frac{\mathrm{MN}}{\mathrm{D}}\right)+\mathrm{g} \mathrm{D}\left(\frac{\partial \eta}{\partial \mathrm{x}}\right)+\left(\frac{\mathrm{gn}^{2}}{\mathrm{D}^{7 / 3}}\right) \mathrm{M}\left[\left(\mathrm{M}^{2}+\mathrm{N}^{2}\right)\right]^{1 / 2}=0$

*The name and style of Spelling used by authors

$\frac{\partial \mathrm{N}}{\partial \mathrm{t}}+\frac{\partial}{\partial \mathrm{x}}\left(\frac{\mathrm{MN}}{\mathrm{D}}\right)+\frac{\partial}{\partial \mathrm{y}}\left(\frac{\mathrm{N}^{2}}{\mathrm{D}}\right)+\mathrm{g} \mathrm{D}\left(\frac{\partial \eta}{\partial \mathrm{y}}\right)+\left(\frac{\mathrm{gn}^{2}}{\mathrm{D}^{7 / 3}}\right) \mathrm{N}\left[\left(\mathrm{M}^{2}+\mathrm{N}^{2}\right)\right]^{1 / 2}=0$

where $\mathrm{M}$ and $\mathrm{N}$ are the volume flux per unit length in the $\mathrm{x}$ and $\mathrm{y}$ directions respectively; They are related to the depth averaged velocities by the relations, $\quad M=u(h+\eta)=u D$ and $N=v(h+\eta)=v D$, where $h$ is the mean sea depth and $\eta$ is the water elevation, $D$ is the total water depth and $g$ the acceleration due to gravity.

\section{MITIGATION}

4.1 Mitigation of Risks and Hazards: As one cannot predict an earthquake and hence a tsunami, a well planned mitigation is of great importance. The main damage from tsunami comes from the destructive nature of the waves themselves. Secondary effects include the debris acting as projectiles which then run into other objects, erosion that can undermine the foundations of structures built along coastlines, and fires that result from disruption of gas and electrical lines. Tertiary effects include loss of crops and water and electrical systems which can lead to famine and disease.

Within the last century, up until the December 2004 tsunami, there were 94 destructiv tsunami which resulted in 51,000 deaths. Despite the fact that tsunami warning systems have been in place in the Pacific Ocean basin since 1950 , deaths still result from tsunami, especially when the source of the earthquake is so close to a coast that there is little time for a warning, or when people do not heed the warning or follow instructions associated with the warning. These factors point out the inadequacy of the world in not having a tsunami warning system in place in the Indian Ocean, where in one event, the death toll from tsunami was increased by a factor of 5 over all previous events.

. In earthquake prone countries which are islands like Japan, walls of height about 5 meters are built along the coast. In some localities, they have built floodgates and channels to redirect the water from the incoming tsunamis.

4.2 Protection by Mangroves: Hock Lye Koh, et al. have discussed the mitigation and protective measures from the tsunamis by planting mangroves and other vegetation throughout the coast. A numerical simulation model developed within the framework of TUNA, the continuity and momentum equations in flux forms in the x-direction are expressed by the following equations:

$$
\begin{aligned}
& \frac{\partial \eta}{\partial t}+\frac{\partial M}{\partial x}=0 \quad \ldots(8) \\
& \frac{\partial M}{\partial t}+\frac{\partial}{\partial x}\left(\frac{M^{2}}{D}\right)+g D\left(\frac{\partial \eta}{\partial x}\right)+\frac{g n^{2} M|M|}{D^{7 / 3}}+\frac{C_{D}}{2} A_{0}\left(\frac{M \mid M}{D^{2}}\right)+C_{M}\left(\frac{V_{0}}{V}\right)\left(\frac{\partial M}{\partial t}\right)=0
\end{aligned}
$$

and the drag coefficient is, $\mathrm{C}_{\mathrm{D}}=8.4\left(\frac{\mathrm{V}_{0}}{\mathrm{~V}}\right)+0.66\left[0.01 \leq\left(\frac{\mathrm{V}_{0}}{\mathrm{~V}}\right) \leq 0.07\right]$ 
The various quantities in the above equations are:

$$
\begin{aligned}
& \mathrm{M} \rightarrow \text { Flow flux in } \mathrm{m}^{2} / \mathrm{s} \\
& \mathrm{D} \rightarrow \text { Total water depth }=(\mathrm{h}+\eta) \text { in } \mathrm{m} \\
& \mathrm{h} \rightarrow \text { Still water depth in } \mathrm{m} \\
& \mathrm{n} \rightarrow \text { Manning coefficient } \\
& \mathrm{g} \rightarrow \text { Acceleration due to gravity in } \mathrm{m} / \mathrm{s}^{2} \\
& \mathrm{C}_{\mathrm{D}} \rightarrow \text { Drag coefficient } \\
& \mathrm{A}_{0} \rightarrow \text { Area of trees under water surface per } 100 \mathrm{~m}^{2} \\
& \mathrm{~V}_{0} \rightarrow \text { Total volume of tree under water surface in } \mathrm{m}^{3} \\
& \mathrm{~V} \rightarrow \text { Control volume in } \mathrm{m}^{3} \\
& \mathrm{C}_{\mathrm{M}} \rightarrow \text { Inertia coefficient }
\end{aligned}
$$

The last term in equation (5) is the mangrove friction term. The inertia coefficient $C_{M}$ is worked out and found to be 1.7 and the non-linear shallow water equations (4) and (5) are solved by method of finite differences.

The situations when the wave approaches a mangrove obstacle are shown in Fig.11. As the wave approaches initially at the mangrove, there is a slight increase in amplitude (Fig. a). The flow from back gets added and the amplitude further increases to larger heights (Fig. b). The flow then retards with almost horizontal wavelets. (Fig.c)

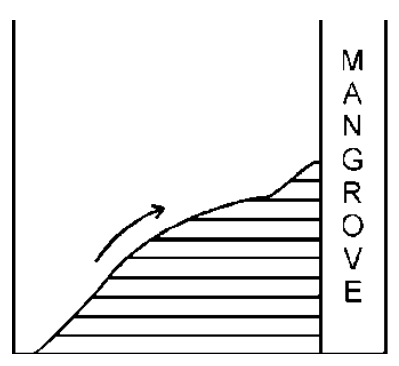

(a)Wave just approaching a

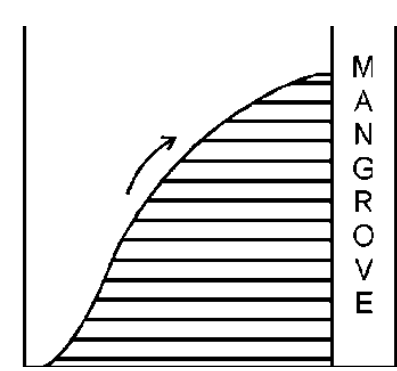

(b) Amplitude increases

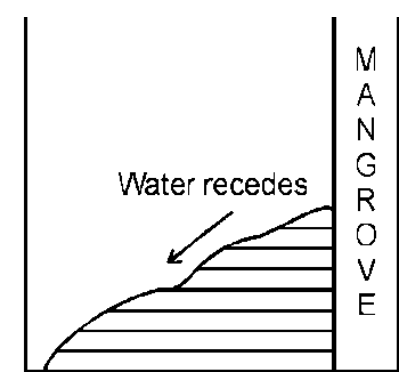

(c) Water starts receding

Fig.11. Situations when a Tsunami approaches a forest of Mangroves

4.3 Prediction and Warning: For areas located at great distances from earthquakes that could potentially generate a tsunami there is usually plenty of time for warnings to be sent and coastal areas evacuated, even though tsunami travel at high velocities across the oceans. Hawaii is good example of an area located far from most of the sources of tsunami, where early warning is possible and has saved lives. For earthquakes occurring anywhere on the subduction margins of the Pacific Ocean there is a minimum of 4 hours of warning before a tsunami would strike any of the Hawaiian Islands.

The National Oceanic and Atmospheric Administration (NOAA) [7] has set up a Pacific warning system (Fig.12) for areas in the Pacific Ocean, called the Pacific Tsunami Warning Center. It consists of an international network of seismographic stations, and tidal stations around the Pacific basin that can all send information via satellite to the Center located in Hawaii. When an earthquake occurs somewhere in the region, the Center immediately begins to analyze the data looking for signs that the earthquake could have generated a tsunami. The tidal stations are also monitored, and if a tsunami is detected, a warning is sent out to all areas on the Pacific coast. It takes at least 1 hour to assimilate all of the information and issue a warning. Thus for an average velocity of a tsunami of $750 \mathrm{~km} / \mathrm{hr}$, the regional system can provide a warning sufficient for adequate evacuation of coastal areas within $750 \mathrm{~km}$ of the earthquake. In the figure is covered regions up to $60^{\circ}$ north and south of the equator and $180^{\circ}$ east and $150^{\circ}$ west of the Greenwich Meridian

In order to be able to issue warnings about tsunami generated within 100 to $750 \mathrm{~km}$ of an earthquake, several regional warning centers have been set up in areas prone to tsunami generating earthquakes. These include centers in Japan, Kamchatka, Alaska, Hawaii, French Polynesia, and Chile. 


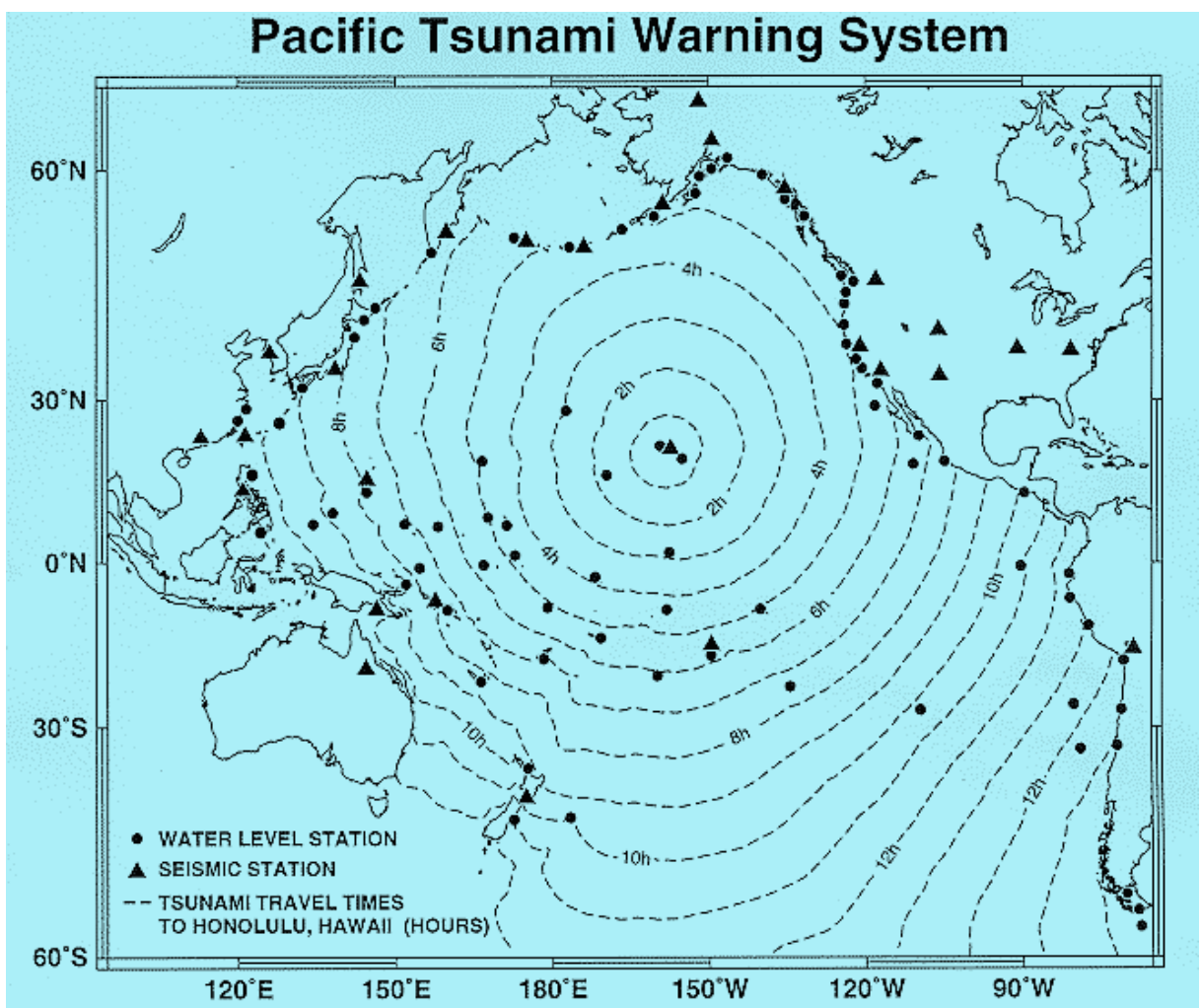

Fig.12 The Pacific Tsunami Warning System [7]

4.31 Use of Computers: The arrival of an incoming tsunami can be predicted with the help of Computers. Bottom pressure sensors relay information in real time. Based on the ptressure readings, the seismic information, the shape of the sea shore and the coastal topography, the computer models can estimate the amplitude and surge height of an approaching tsunami. The prediction can be done within minutes.

In Fig13 is shown a deep water buoy used in the tsunami warning system. The principle is that bottom pressure sensors attached to the buoys, constantly monitor the pressure of the overlying water column.

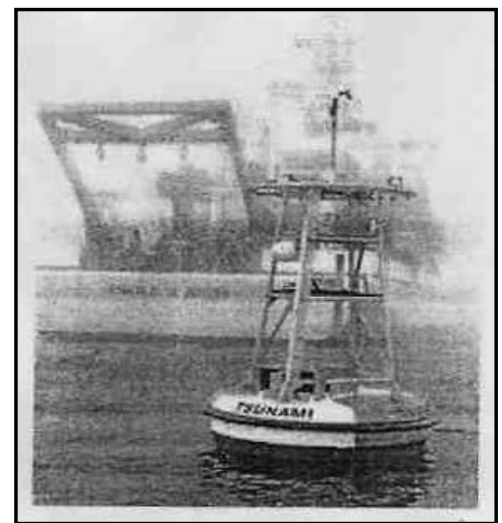

Fig.13 A deep water buoy used for the Tsunami warning

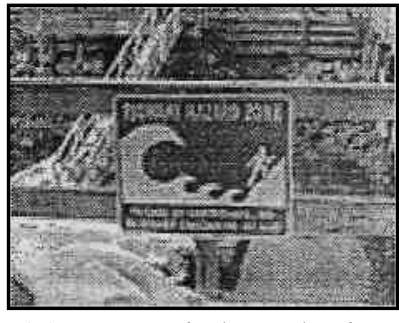

Fig.15 Tsunami hazard sign at Bamfield, British Columbia

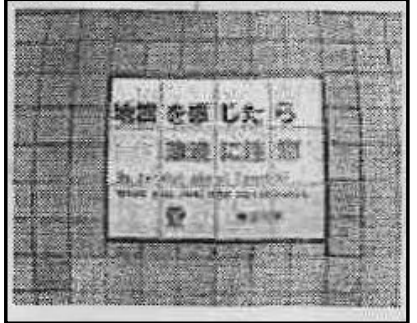

Fig.16 A tsunami warning on a seawall in Kamakura, Japan 2004

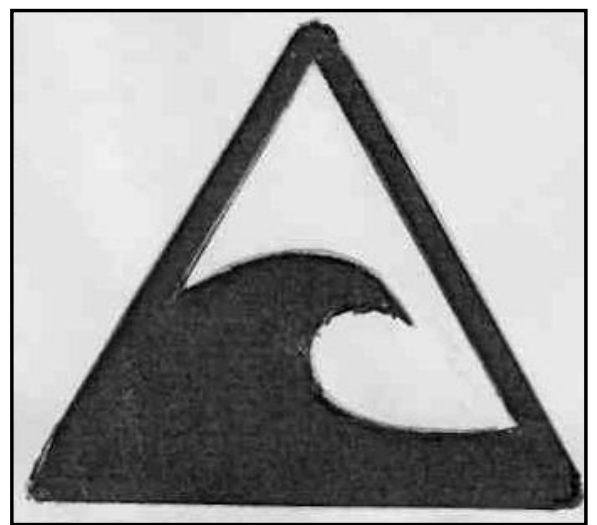

Fig.14 An international tsunami warning sign

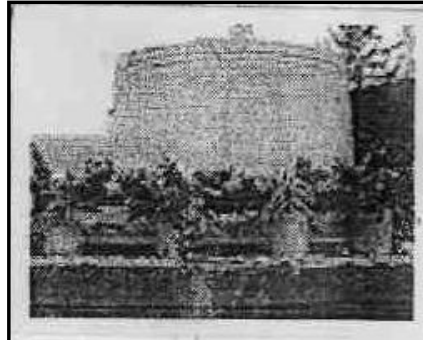

Fig.17Monument to the victims of tsunami at Laupahoehoe, Hawaii, US 


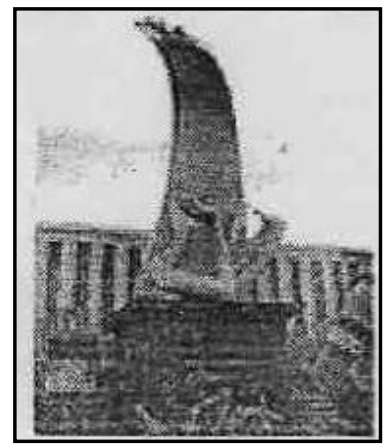

Fig.18 Tsunami Memorial at Kanyakumari Beach, India

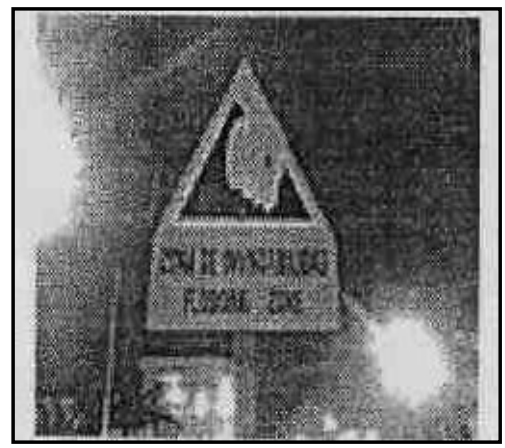

Fig.19 A Tsunammi-Hazard-Zone Sign both in Spanish and English in Iquique, Chile

In Figures 14 to 19 (All credits: [8]) are shown some of the warning signs along with some monuments. The pictures being small, the writings are not clear. In some are mentioned the escape routes. The sirens are fitted on hill tops.

A warning issued by Japan which appeared in the Indian daily, the Times of India, Mumbai [11] under the heading, "Japan warns of future risk of 112 feet high Tsunami" and reported from Tokyo, Japan is worth quoting here in Italics.

"Tokyo:- "A 34 metre (112 feet) tsunami could hit the Japanese coast in the wake of a massive earthquake, an expert panel has said after revising its worst case scenario projections following last year's disaster.

If a 9.0 magnitude quake struck in the Nankai Trough off central to western Japan huge swathes of Pacific coastline could be inundated, with over 20 metre waves hitting areas from Tokyo to the south-western island of Kyushu.

At the town of Kuroshio in south-western Kochi prefecture the tsunami could reach 34.4 metres - the highest level projected under the scenario, the cabinet office panel said late on Saturday (31 March 2012).

And at the now offline Hamaoka nuclear plant in central Shizuoka prefecture, the tsunami could be as high as 21 metres, breaching the 18-metre breakwater that operators are currently constructing, the panel said. In its previous projection in 2003 the panel gave a worst case scenario in which no areas would be hit by a tsunami of more than 20 metres. But the panel has upgraded its predictions in the wake of the 9.0 magnitude earthquake on March 11 last year (2011) that sent a tsunami barreling into the north-east, killing some 19,000 people and devastating the coastline.

The panel said that it will continue studying the extent of areas that could be hit by a tsunami, while the government will examine the emergency disaster measures based on the latest estimation." AFP.

4.4 Tsunami Safety Rules: Stephen Nelson [6] has enumerated a number of safety rules as a protection from the tsunamis.

- People in the coastal regions should always be prepared for a tsunami emergency

- Immediately after an earthquake, quickly move to higher ground and away from the coast

- The delta regions of rivers are as dangerous as the ocean

- Co-operate with the local authorities and wait for the "ALL CLEAR" sign

- As a tsunami can move faster than one can run, never go to watch a tsunami

- Corners in the rooms of buildings are safer than open spaces in them

- If you are in a boat or ship, immediately anchor them and run away to open spaces far away from the coast

- Stay tuned to your radio or TV telecast for instructions to be followed 


\section{International Advanced Research Journal in Science, Engineering and Technology}

ISO 3297:2007 Certified

Vol. 5, Issue 1, January 2018

\section{CONCLUSION}

Author's [5] conclusion is worth the matter to fit in here.

Oh! What a great physical process the almighty has created. Danger to property and death to millions! Tsunami not being of frequent occurrence, the seriousness comes only when the damage and destruction go beyond description. Being a process beyond control and no existing prevention, it is the work of mankind to prepare themselves not to get affected by the fury of the process. The implied meaning being that one has to fight against nature. A Herculian task indeed!

In what way an earthquake is disastrous, in the same manner a tsunami is equally disastrous. In fact, the latter is little more as the energy is carried by water waves affecting the coastal areas of other countries. The disaster from an earthquake may be confined to areas in the land surrounding the epicenter. Prediction of a tsunami can be almost the same as that of an earthquake in a restricted sense because the epicenter being under the sea bed, special instruments are required for detection of signals. Hence mitigation is the only solution. Only try to reduce the damage caused by it. In Japan at many places in the coastal areas are built walls of height about 5 meters in order to protect populated coastal areas. In some places flood gates have been built and channels to redirect the water from the incoming tsunami. But, such things are of not much use. For example, the 12 July 1993 earthquake that struck Okushiri of Hokkaido in Japan generated a tsunami of height about 30 meters almost the height of a 10 storey building.

Planting mangroves throughout the coastal areas as mentioned in the literature review of this paper is a good proposition. What is needed is to weaken the initial thrust of the tsunami. The danger will be more if the crest of the tsunami first reaches the shore. On the contrary, when a trough approaches first, it gives sufficient time for preparation for the people to protect themselves. The protection can be done by not only planting mangroves but even by thick forestation of the coastal areas. People want to enjoy the good breeze of the beach and stay in hotels and resorts facing the sea. Why not to build them few $\mathrm{km}$ away from the shore? Start a good town planning right now or earliest the better. As there is no prevention, the cure has to be highly effective. One can think of some rock structures of sufficient height which are of just monumental value and not any residential put up throughout the coastal areas. Let the tsunami come and clean those structures. The population should be few kms. away from the shore. The farthest the better. If we start now, the success will be at least after a quarter century and beneficial for the future generation. How many people will agree with my proposition has to be seen only after going through this chapter of my thesis.

Let us be blessed with methods to control this infamous deadly divine weapon.

\section{REFERENCES}

[1] Campbell Phillips, Editor, Writer and Researcher from Richmond, Victoria, Australia. 16 March 2011

[2] Christiansen Eric, H and W. Kenneth Hamblin; “Earth's Dynamic Systems”, Ch. 18, 'Seismicity and Earth's Interior', p.516.

[3] Koh Hock Lye, Su Yean The, Taksiah A, Majid, Tze Liang Lau and Fauziah Ahmad; "Earthquake and Tsunami Research in USM : The Role of Disaster Research Nexus", 12 September 2011, p.151-163.

[4] Miller Derek K. "Learning about tsunami from the Indian Ocean Disaster of December 2004" March 2008, p.83-94.

[5] Nair Vadakke Chundayil Achuthan Kutty, JJT University, Rajasthan, India. "A Perspective View of Physical Processes and their effects taking place in the Earth right from its formation" Ch.5. Tsunamis, July 10, 2013.

[6] Nelson Stephen A(Prof.). of Tulane University. "Natural Disasters", Updated 16 Sep.2016

[7] NOAA, USGS, Humboldt State University

[8] Pararas Carayannis George; "A historical summary of early Tsunami Research in the U.5." November 2011 (date taken out from reference), 19 pages.

[9] The Times of India, Mumbai dated 12 March 2011.

[10] The Times of India, Mumbai (Date unrecorded).

[11] The Times of India, Mumbai dated 2 April 2012.

\section{BIOGRAPHY}

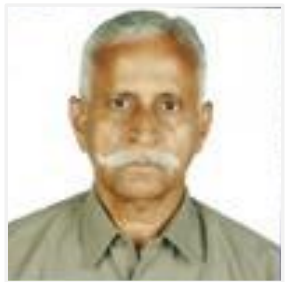

*Dr.(Prof.) V.C.A. Nair (b.15th Aug. 1939) is an Educational Physicist, Counselor, Research Guide and Consultant. He did his Masters in Physics from Mumbai University, India and Ph.D. from JJT University, Rajasthan also in India $\mathrm{He}$ is a Research Guide and distinguished alumni of JJT University. He is also a Chancellor designated Resource Person in the area of Physics in the University. He has to his credit over 4 decades of teaching Applied Physics in eminent Polytechnics in Mumbai and having taught nearly 16,000 students since 1965 . He has published a number of research papers in Physics and Geophysics in International and UGC recognized Journals some of which can be seen in the net 'Google Search' when the name of the author is typed in that style. He is a Life Member of Indian Society for Technical Education which is an all India body. He had been to USA a number of times and visited eminent Universities such as Stanford, Harvard, MIT, University of California both at Berkeley and Los Angeles and University of San Francisco. At present Dr. Nair is a Research Guide for Physics at JJT University, Rajasthan-333001, India . He is member of the Editorial Board of this Journal. His Ph.D. Thesis is in Geophysics and he is working on topics such as Tides, Clouds, Global Warming and Climate Change. - Editor.

*nairvca39@gmail.com. 